\title{
Flexural Strength Evaluation of Reinforced Concrete Members with Ultra High Performance Concrete
}

\author{
Baek-Il Bae, ${ }^{1}$ Hyun-Ki Choi, ${ }^{2}$ and Chang-Sik Choi ${ }^{3}$ \\ ${ }^{1}$ Research Institute of Industrial Science, Hanyang University, 17 Haengdang-Dong, Seongdong-Gu, Seoul 04763, Republic of Korea \\ ${ }^{2}$ Department of Fire and Disaster Prevention Engineering, Kyungnam University, Gyeongsangnam-do 51767, Republic of Korea \\ ${ }^{3}$ Department of Architectural Engineering, Hanyang University, 17 Haengdang-Dong, Seongdong-Gu, Seoul 04763, Republic of Korea
}

Correspondence should be addressed to Hyun-Ki Choi; chk7796@kyungnam.ac.kr

Received 25 September 2015; Revised 5 December 2015; Accepted 7 December 2015

Academic Editor: Stefano Sorace

Copyright (C) 2016 Baek-Il Bae et al. This is an open access article distributed under the Creative Commons Attribution License, which permits unrestricted use, distribution, and reproduction in any medium, provided the original work is properly cited.

\begin{abstract}
Flexural strength evaluation models for steel fiber reinforced ultra high strength concrete were suggested and evaluated with test results. Suggested flexural strength models were composed of compression stress blocks and tension stress blocks. Rectangular stress block, triangular stress block, and real distribution shape of stress were used on compression side. Under tension, rectangular stress block distributed to whole area of tension side and partial area of tension side was used. The last model for tension side is realistic stress distribution. All these models were verified with test result which was carried out in this study. Test was conducted by four-point loading with $2,000 \mathrm{kN}$ actuator for slender beam specimen. Additional verifications were carried out with previous researches on flexural strength of steel fiber reinforced concrete or ultra high strength concrete. Total of 21 test specimens were evaluated. As a result of comparison for flexural strength of section, neutral axis depth at ultimate state, models with triangular compression stress block, and strain-softening type tension stress block can be used as exact solution for ultra high performance concrete. For the conservative and convenient design of section, modified rectangular stress block model can be used with strain softening type tension stress block.
\end{abstract}

\section{Introduction}

Usually, flexural strength of normal strength concrete members is designed using rectangular stress block parameters. Current design codes provide the rectangular stress block parameters for simplified design methodology. However, these stress blocks are determined by tests of reinforced concrete columns and they have apparent limitations. Rectangular stress block can be used because the shape of stressstrain relation of concrete is similar to the trapezoid. However, shape of stress-strain relationship of concrete changed into triangle as increase of compressive strength of concrete. For this reason, rectangular stress block parameters depend on the compressive strength of concrete. For example, the current ACI code [1] suggests that higher value of compressive strength of concrete can be used as 0.85 times the specified compressive strength of concrete. And the depth of rectangular stress block has the lower bound of 0.65 at $76 \mathrm{MPa}$ of compressive strength of concrete. Ultimate strain of concrete is suggested by value of 0.003 . These values are determined from test results of normal strength concrete. However, depending on the compressive strength, mechanical properties and failure type of concrete are changed.

Generally, after experiencing peak stress, sudden drop of load resistance can be observed. Ultra high strength concrete also failed with this failure mode. Making brittle failure of ultra high strength concrete matrix more ductile, under compression, steel fiber can be included in the matrix. Inclusion of steel fiber can change the explosive failure of ultra high strength concrete and provide higher tensile strength and deformability. So steel fiber is usually used for ultra high strength concrete matrix.

Ultra high performance concrete usually has much higher compressive strength and tensile strength than normal strength concrete, generally ranging from 100 to $200 \mathrm{MPa}$. Shape of stress distribution in compression side of section and tensile strength of concrete shall be considered in section design. Design guidelines for ultra high performance 
concrete suggested the way to design the section of member suggested stress-strain relation. However, stress-strain relation for ultra high performance concrete needs specific test results not using stress blocks or assumptions. Therefore, in this study, various types of compression and tension stress block combinations were evaluated with experimental result and previous research results for easy and safe design of ultra high performance concrete members.

\section{Review of Current Design Codes for Flexural Strength of Ultra High Performance Concrete}

Reinforced concrete members using normal strength concrete are designed with an assumption that stress distribution can be shaped with rectangle and concrete cannot transfer the tensile stress. However, these assumptions cannot be applied to flexural strength calculation of ultra high performance concrete members. Since ultra high performance concrete has much higher compressive strength than normal strength concrete and usually reinforced with steel fiber, shape of stress distribution in compression side will be changed and tensile stress distribution in tension side should be considered, in order to calculate the flexural strength of section. Some of design guidelines for high strength concrete or steel fiber reinforced concrete have different assumptions for flexural strength calculation. They can be categorized into two groups: one uses stress block parameters and the other uses specified stress-strain relation of concrete.

Current design code ACI318 [1] suggests that flexural strength of reinforced concrete section can be calculated by

$$
M_{n}=A_{s} f_{y}\left(d-\frac{a}{2}\right)
$$

In this equation, $a$, depth of rectangular stress block, can be determined by using stress block parameter $\beta_{1}$. For compressive strength of concrete between 17 and $28 \mathrm{MPa}, 0.85$ can be used as the value of $\beta_{1}$. $\beta_{1}$ shall be decreased linearly a rate of 0.05 for each $7 \mathrm{MPa}$ of compressive strength of concrete above $28 \mathrm{MPa}$ of compressive strength of concrete. The smallest value of $\beta_{1}$ is 0.65 .

As can be seen in ACI318 [1], current design code provisions did not consider the effect of steel fiber. Some of design guidelines suggested the way to calculate flexural strength of steel fiber reinforced concrete section. ACI 544 committee [2] provides the flexural strength equations by adopting research results of Henager and Doherty [3], especially for rectangular section member

$$
M_{n}=A_{s} f_{y}\left(d-\frac{a}{2}\right)+\sigma_{t} b(h-e)\left(\frac{h}{2}+\frac{e}{2}-\frac{a}{2}\right) \text {, }
$$

where $M_{n}$ is nominal flexural strength of section, $f_{y}$ is yield strength of steel rebar, $d$ is effective depth of section, $a$ is depth of stress block, $h$ is height of section, $e=\left(\varepsilon_{s}\right.$ (fibers) + $0.003)(c / 0.003), \varepsilon_{s}$ is strain in tension side, $\varepsilon_{s}($ fiber $)=\sigma_{f} / E_{s}$, $c$ is neutral axis depth, and tensile strength of steel fiber reinforced concrete can be calculated using

$$
\sigma_{t}=0.00772 \frac{l_{f}}{d_{f}} \rho_{f} F_{\mathrm{be}}
$$

where $l_{f}$ is length of steel fiber, $d_{f}$ is diameter of steel fiber, $\rho_{f}$ is percent by volume of steel fiber, and $F_{\text {be }}$ is bond efficiency factor.

Imam et al. [4] suggested the modified ACI 544 [2] model which can be used as steel fiber reinforced concrete with high strength matrix. Imam et al. investigated the bond stress between steel fiber and matrix. They suggested that tensile stress block height coefficient should be changed into 0.02. According to this modification, tensile strength can be calculated using

$$
\sigma_{t}=2 F, \quad F=\frac{l_{f}}{d_{f}} V_{f} \eta_{f}
$$

where $V_{f}$ means volume fraction of steel fiber $\left(=\rho_{f} / 100\right)$ and $\eta_{f}$ is fiber factor $(1.0 \sim 1.2)$. Moment capacity of section can be determined according to ACI 544 [2], (2).

Lim et al. [5] suggested that stress block parameters should be reevaluated with change of matrix and steel fiber. They use $\alpha_{1}$ as 0.90 because steel fiber can provide more ductility under compression either. Tensile strength of steel fiber reinforced concrete can be determined using

$$
\sigma_{t u}=\eta_{0}^{\prime} \eta_{1} V_{f} l_{f} \frac{\tau_{u}}{2 r}
$$

where $\eta_{0}^{\prime}$ is steel fiber orientation factor, $\eta_{1}$ is length efficiency factor, $\tau_{u}$ is average ultimate bond stress at the fiber-matrix interface, and $r$ is the ratio of the fiber cross-sectional area to its perimeter. Since Lim et al. [5] developed their model with plasticity approach, they use whole area over the neutral axis as compressive stress block. Neglecting cover thickness and considering tensile stress block in tension side of section, neutral axis depth $x$ can be calculated using

$$
x=\frac{d \sigma_{t u}+f_{y} / b}{\alpha_{1} \sigma_{c u}+\sigma_{t u}}
$$

where $\sigma_{c u}$ is compressive strength of concrete, $b$ is width of section, and $f_{y}$ is yield strength of reinforcement. From (6) internal moment arm can be calculated

$$
h=d-\frac{x}{2}
$$

where $d$ is effective depth of section. Using (5), (6), and (7) flexural capacity of section can be calculated by using

$$
M_{u}=f_{y} h+\sigma_{t u} \frac{b}{2}\left(h^{2}-\frac{x^{2}}{4}\right) .
$$

Although stress block approach is easy to use for flexural strength calculation, it cannot consider the difference of concrete with higher strength matrix or other characteristics. 


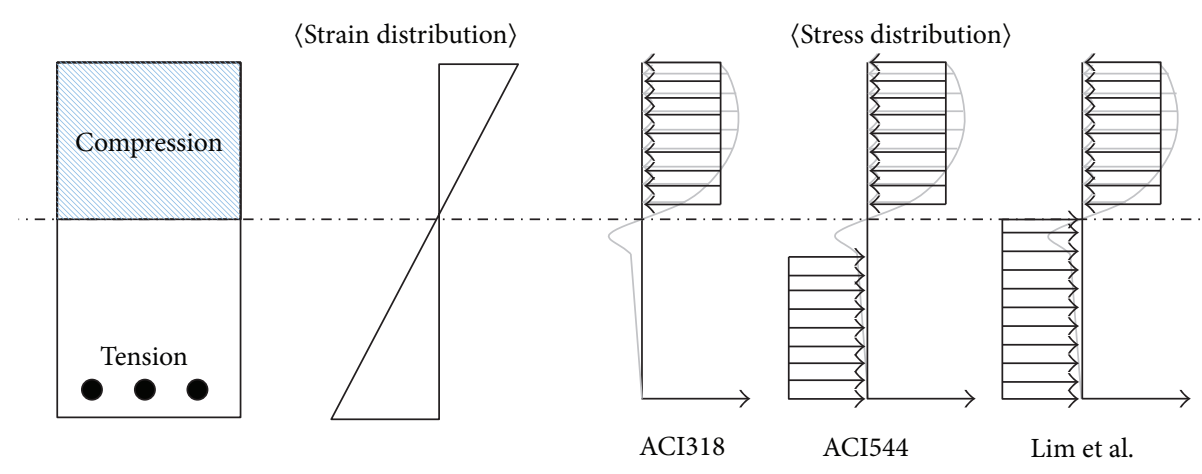

FIGURE 1: Previously suggested stress block combination.

Flexural strength calculation models for normal strength concrete and steel fiber reinforced concrete were illustrated in Figure 1. The main difference between normal strength concrete model and steel fiber reinforced concrete model is existence of tensile stress block. Difference among steel fiber reinforced concrete models is the range of tensile stress distribution. However, they are not exact models because stress distribution might be changed with compressive strength of matrix and tensile stress distribution is more comprehensive than used in Figure 1.

For the exact solution for flexural strength of section, comprehensive stress-strain relations are directly applied to calculate the flexural strength of section. The representative models considering real stress distribution are provided by RILEM $\sigma-\varepsilon$ method [9], EC2 flexural analysis [10], and AFGC-Setra guideline [11]. They can provide more accurate value than flexural strength model made up of stress blocks. However, they need more comprehensive computation process and some material test.

\section{Flexura Strength Calculation Model}

According to the material test about ultra high performance concrete, most of stress-strain relation shapes are triangular under compression. Therefore, under compression, triangular stress block may be used for the design of ultra high performance concrete flexural members. Previous research [12] suggested rectangular stress block parameters for high strength and ultra high strength concrete. However, most of code provisions use the rectangular stress block parameters because they mainly focused on the use for normal strength concrete. They consider the shape of stress-strain relation using various value of $\beta_{1}$, depending on compressive strength of concrete. Rectangular stress block slightly overestimates the flexural strength of concrete member especially for high reinforcement ratio and compressive strength of concrete. As can be seen in Section 2, tensile stress block for steel fiber reinforced concrete has been shown in various shape and size. Therefore, designing ultra high performance concrete members, stress block parameters should be reorganized.

In this study, three types of stress block parameters were considered: ACI stress block parameters, stress block parameters from UHPC member design guideline, and triangular stress block determined by maximum compressive

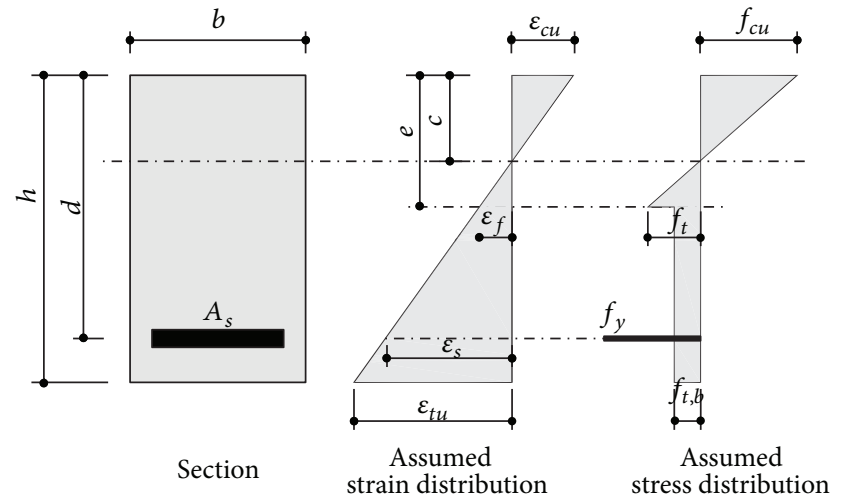

FIGURE 2: Strain and stress distribution of ultra high performance concrete section.

strength and corresponding strain resulting from material tests. Tensile behavior of steel fiber reinforced concrete was divided into strain hardening, strain softening, and fully plastic behavior, three types. In this study tensile stress blocks were composed of these three types of tensile behavior of steel fiber reinforced concrete.

Strain and stress distribution of ultra high performance concrete section were shown in Figure 2. In this study three types of stress blocks were used under compression and tension, respectively. Total of 9 types of flexural strength models were investigated. These models were illustrated in Figure 3. The most important design parameter for flexural strength is neutral axis depth. Neutral axis depth for 9 types of flexural strength model was developed as follows:

$$
\begin{aligned}
& c_{c 1}=\frac{A_{s} f_{y}-\gamma h f_{t} b}{0.5 f_{c}^{\prime} b-0.5(\eta-1) f_{t} b-\gamma \eta f_{t} b}, \\
& c_{c 2}=\frac{A_{s} f_{y}+0.5(1+\gamma) f_{t} b h}{0.5 f_{c}^{\prime} b-0.5(\eta-1) f_{t} b+0.5 \eta(1+\gamma) f_{t} b}, \\
& c_{c 3}=\frac{A_{s} f_{y}+\gamma f_{t} h b}{0.5 f_{c}^{\prime} b+\gamma \eta f_{t} b}, \\
& c_{c 4}=\frac{A_{s} f_{y}+\gamma f_{t} b h}{\alpha_{1, \mathrm{ACI}} f_{c}^{\prime} \beta_{1, \mathrm{ACI}} b-0.5(\eta-1) f_{t} b+\gamma \eta f_{t} b},
\end{aligned}
$$




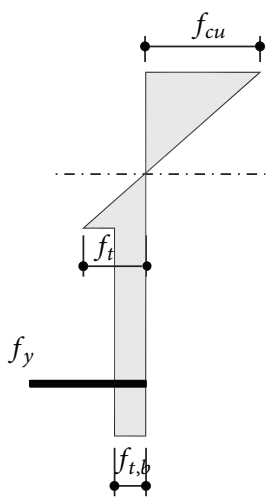

(a) Type 1

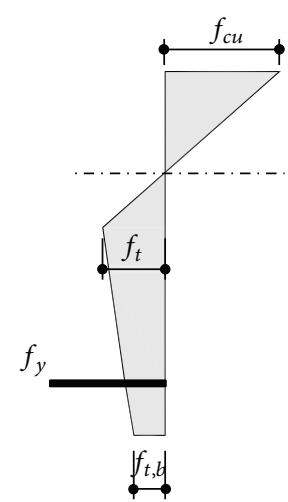

(b) Type 2

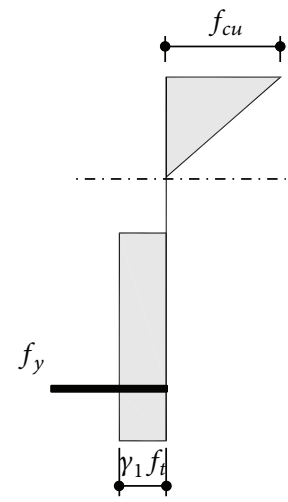

(c) Type 3

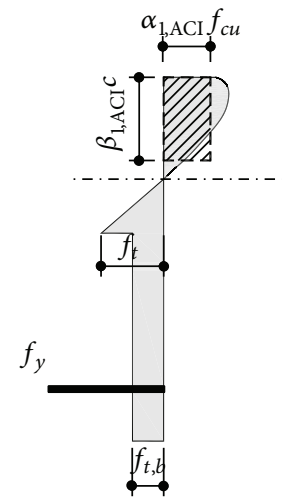

(d) Type 4

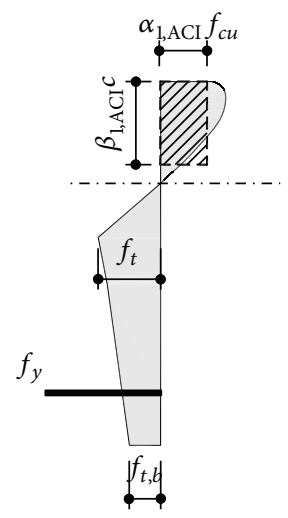

(e) Type5

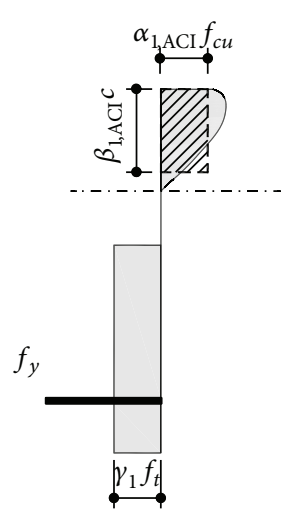

(f) Type 6

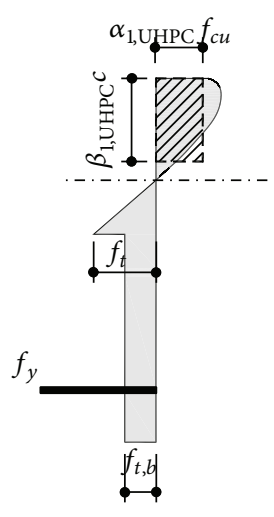

(g) Type 7

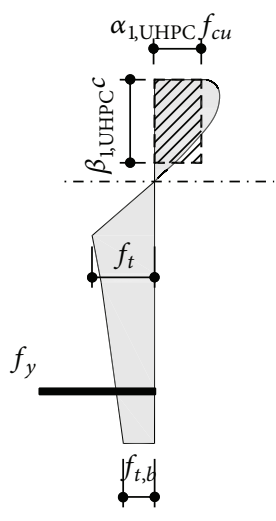

(h) Type 8

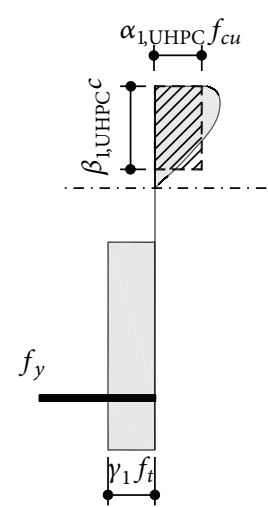

(i) Type 9

Figure 3: Stress block models.

$$
\begin{aligned}
& c_{c 5}=\frac{A_{s} f_{y}+0.5(1+\gamma) f_{t} b h}{\alpha_{1, \mathrm{ACI}} f_{c}^{\prime} \beta_{1, \mathrm{ACI}} b-0.5(\eta-1) f_{t} b+0.5 \eta(1+\gamma) f_{t} b}, \\
& c_{c 6}=\frac{A_{s} f_{y}+\gamma f_{t} h b}{\alpha_{1, \mathrm{ACI}} f_{c}^{\prime} \beta_{1, \mathrm{ACI}} b+\gamma \eta f_{t} b} \text {, } \\
& c_{c 7}=\frac{A_{s} f_{y}+\gamma f_{t} b h}{\alpha_{1, \mathrm{UHPC}} f_{c}^{\prime} \beta_{1, \mathrm{UHPC}} b-0.5(\eta-1) f_{t} b+\gamma \eta f_{t} b}, \\
& c_{c 8} \\
& =\frac{A_{s} f_{y}+0.5(1+\gamma) f_{t} b h}{\alpha_{1, \mathrm{UHPC}} f_{c}^{\prime} \beta_{1, \mathrm{UHPC}} b-0.5(\eta-1) f_{t} b+0.5 \eta(1+\gamma) f_{t} b}, \\
& c_{c 9}=\frac{A_{s} f_{y}+\gamma f_{t} h b}{\alpha_{1, \mathrm{UHPC}} f_{c}^{\prime} \beta_{1, \mathrm{UHPC}} b+\gamma \eta f_{t} b},
\end{aligned}
$$

where $f_{c}^{\prime}$ is compressive strength of concrete, $A_{s}$ is area of tensile rebar, $f_{y}$ is yield strength of steel rebar, $f_{t}$ is ultimate tensile strength of concrete, $\gamma$ is ratio between post cracking tensile strength and ultimate tensile strength, $\eta$ can be defined by $\varepsilon_{f} / \varepsilon_{c u}+1, \alpha_{1}$ and $\alpha_{1, \mathrm{UHPC}}$ are rectangular stress block parameter for compressive strength of concrete for normal strength concrete and UHPC, respectively, $\beta_{1}$ and $\beta_{1, \mathrm{UHPC}}$ are stress block depth parameter for normal strength concrete and UHPC, respectively, $b$ is width of section, and $d$ is effective depth of section. $\varepsilon_{f}$ for $\eta$ is strain corresponding to ultimate tensile strength and $\varepsilon_{c u}$ is ultimate compressive strain of concrete.

The most difficult and controversial part is the determination of tensile strength of fiber reinforced concrete. Swamy and Al-Ta'an [13] suggested the equation according to the composite theory as follows:

$$
f_{t}=0.970 f_{r}\left(1-V_{f}\right)+2 V_{f} \frac{L_{f}}{D_{f}} \text {, }
$$

where $f_{r}$ is modulus of rupture of concrete and other variables are fiber geometry defined in Section 2.

Using neutral axis depth defined in (9) considering shape of stress block, nominal flexural strength of ultra high performance concrete members can be calculated as follows:

Case 1. Consider

$$
\begin{aligned}
M_{n}= & \left(\frac{f_{c k} c b}{2}\right) \frac{2}{3} c+\left\{f_{t}(e-c) b\right\} \frac{2}{3}(e-c) \\
& +\left\{\gamma f_{t}(h-e) b\right\}\left(e-c+\frac{h-e}{2}\right) \\
& +A_{s} f_{y}(d-c) .
\end{aligned}
$$


TABLE 1: Mix proportions.

\begin{tabular}{|c|c|c|c|c|c|c|c|c|}
\hline \multirow{2}{*}{$w / b$} & \multicolumn{5}{|c|}{ Weight ratio } & \multirow{2}{*}{$\begin{array}{c}\text { Steel fiber } \\
(\%)\end{array}$} & \multirow{2}{*}{$\begin{array}{c}\text { Admixture } \\
(\mathrm{kg})\end{array}$} & \multirow{2}{*}{$\begin{array}{c}f_{c k} \\
(\mathrm{MPa})\end{array}$} \\
\hline & Cement & Water & Silica fume & Sand & Filler (Micro Silica) & & & \\
\hline 0.17 & 1 & 0.21 & 0.24 & 1.04 & 0.31 & 2 & 1.08 & 200 \\
\hline
\end{tabular}

Case 2. Consider

$$
\begin{aligned}
M_{n}= & \left(\frac{f_{c k} c b}{2}\right) \frac{2}{3} c+\left\{f_{t}(e-c) b\right\} \frac{2}{3}(e-c) \\
& +\left\{\gamma f_{t}(h-e) b\right\}\left(e+\frac{h-e}{3}\right)+A_{s} f_{y}(d-c) .
\end{aligned}
$$

Case 3. Consider

$$
\begin{aligned}
M_{n}= & \left(\frac{f_{c k} c b}{2}\right) \frac{2}{3} c+\left\{\gamma f_{t}(h-e)\right\}\left(e-c+\frac{h-e}{2}\right) \\
& +A_{s} f_{y}(d-c) .
\end{aligned}
$$

Cases 4, 7. Consider

$$
\begin{aligned}
M_{n}= & \left(a_{1} f_{c k} \beta_{1} c b\right) \frac{c}{2}+\left\{f_{t}(e-c) b\right\} \frac{2}{3}(e-c) \\
& +\left\{\gamma f_{t}(h-e) b\right\}\left(e-c+\frac{h-e}{2}\right) \\
& +A_{s} f_{y}(d-c) .
\end{aligned}
$$

Cases 5, 8. Consider

$$
\begin{aligned}
M_{n}= & \left(a_{1} f_{c k} \beta_{1} c b\right) \frac{c}{2}+\left\{f_{t}(e-c) b\right\} \frac{2}{3}(e-c) \\
& +\left\{\gamma f_{t}(h-e) b\right\}\left(e+\frac{h-e}{2}\right)+A_{s} f_{y}(d-c) .
\end{aligned}
$$

Cases 6, 9. Consider

$$
\begin{aligned}
M_{n}= & \left(a_{1} f_{c k} \beta_{1} c b\right) \frac{c}{2}+\left\{\gamma f_{t}(h-e)\right\}\left(e-c+\frac{h-e}{2}\right) \\
& +A_{s} f_{y}(d-c) .
\end{aligned}
$$

\section{Flexural Behavior of Ultra High Performance Concrete Members}

4.1. Test Plan. In order to verify the applicability of suggested models, ultra high performance concrete beam was tested. Average ultimate compressive strength of standard cylinder was $216 \mathrm{MPa}$. Splitting strength of standard cylinder is distributed between 7.2 19.5 MPa. Mix proportions for ultra high performance concrete are summarized in Table 1. Mechanical properties of concrete and rebar used in this study were summarized in Tables 2 and 3, respectively.
TABLE 2: Mechanical characteristics of rebar.

\begin{tabular}{lcccc}
\hline Materials & $\begin{array}{c}\text { Yield } \\
\text { strength } \\
(\mathrm{MPa})\end{array}$ & $\begin{array}{c}\text { Yield } \\
\text { strain } \\
\left(\varepsilon_{y}\right)\end{array}$ & $\begin{array}{c}\text { Tensile } \\
\text { strength } \\
(\mathrm{MPa})\end{array}$ & $\begin{array}{c}\text { Poisson's } \\
\text { ratio }\end{array}$ \\
\hline D25 & 422 & 0.0021 & 621 & 0.28 \\
D10 & 384 & 0.0019 & 568 & 0.27 \\
\hline
\end{tabular}

Preventing premature shear failure of specimen, total span of test specimen is reinforced by stirrups with spacing of $150 \mathrm{~mm}$. Stirrups were not located between two loading points. 2,000 kN actuator was used for test and shear-span to depth ratio was 6.5 . In order to verify the neutral axis depth calculation model which was shown in (9), strain gages for concrete were mounted at the concrete surface. Strain gages for steel also can be attached to reinforcement at the center of test specimen. Details of test specimens were illustrated in Figure 4 .

4.2. Test Results. Test specimens have shown the flexural failure pattern. Because of inclusion of steel fiber, crack localization did not occur until crushing of concrete occurred at extreme compression fiber. After initial crack occurred, cracks were spread to outside the maximum bending moment area. After yielding of reinforcement, diagonal tension crack was not observed and cracks were spread to supports. At deflection $98 \mathrm{~mm}$, crushing of concrete occurred and cracks were propagated to crushing area with opening of initial crack. Final stage of failure and load-deflection relation were shown in Figures 5(a) and 5(b), respectively. Maximum load was $179 \mathrm{kN}$ which occurred after yielding of reinforcement. Analyzing strain gauges attached to concrete and reinforcement, neutral axis depth was $123 \mathrm{~mm}$ at peak load stage.

Neutral axis depth is important index for reinforced concrete members because flexural strength and ductility can highly depend on the neutral axis depth of section. Neutral axis depth can be measured by test using the value of strain gauge attached to compression fiber and tension reinforcements. Since strain gauge attached to extreme tensile and compression fiber failed before experiencing peak load, strain of compression and tension reinforcement were used. Curvature at first yield of tension reinforcement was 0.0122 $(1 / \mathrm{m})$ and peak load curvature was $0.019(1 / \mathrm{m})$. Neutral axis depth was $92.5 \mathrm{~mm}$ and $122.8 \mathrm{~mm}$ from extreme compression fiber, respectively. As shown in Figure 6, change of neutral axis depth occurred after yielding of tension reinforcement. After experiencing peak load, neutral axis depth did not change until crushing of concrete in compression side of section occurred. 
TABLE 3: Mechanical characteristics of concrete.

\begin{tabular}{|c|c|c|c|c|}
\hline Stress state & $\begin{array}{l}\text { Ultimate strength } \\
(\mathrm{MPa})\end{array}$ & Young's modulus (MPa) & $\begin{array}{c}\text { Ultimate/cracking } \\
\text { strain }(\% o)\end{array}$ & Poisson's ratio \\
\hline Compression & 216 & \multirow{2}{*}{54,306} & $3.738\left(\varepsilon_{c u}\right)$ & \multirow{2}{*}{0.26} \\
\hline Tension & 9.8 & & $0.221\left(\varepsilon_{t}\right)$ & \\
\hline
\end{tabular}

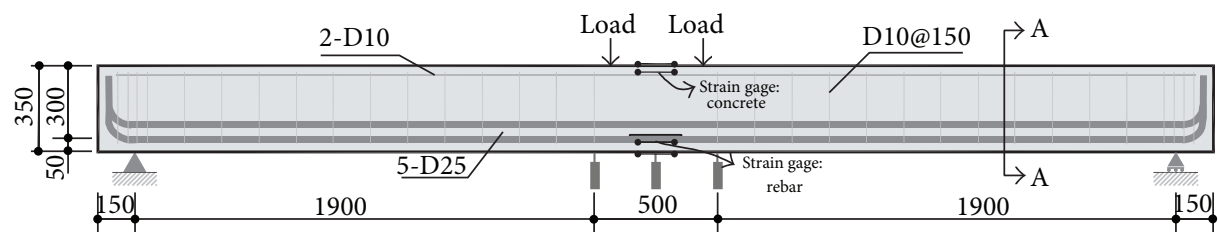

(a) Setting and measurement plan

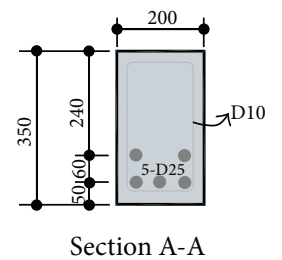

(b) Section

FIGURE 4: Details of test specimen.

TABLE 4: Comparison between test results and assumed model.

\begin{tabular}{lcccc}
\hline Model & $\begin{array}{c}c \\
(\mathrm{~mm})\end{array}$ & $\begin{array}{c}\varepsilon_{s} \\
(\% \mathrm{o})\end{array}$ & $\begin{array}{c}M_{n} \\
(\mathrm{kNm})\end{array}$ & $\begin{array}{c}P_{n} \\
(\mathrm{kN})\end{array}$ \\
\hline Type 1 & 90.88 & 12.3 & 363 & 202 \\
Type 2 & 85.98 & 13 & 296 & 164 \\
Type 3 & 95.03 & 11.8 & 425 & 235 \\
Type 4 & 68.76 & 16.3 & 356 & 197 \\
Type 5 & 78.72 & 14.2 & 297 & 164 \\
Type 6 & 87.39 & 12.8 & 433 & 240 \\
Type 7 & 91.30 & 12.2 & 316 & 175 \\
Type 8 & 98.13 & 11.4 & 308 & 170 \\
Type 9 & 102.28 & 11.0 & 353 & 197 \\
Test results & 93 & 9.10 & 322 & 179 \\
\hline
\end{tabular}

$c$ : neutral axis depth, $\varepsilon_{s}$ : strain at tensile reinforcement at mid length of beam, $M_{n}$ : nominal flexural strength of section (predicted value), and $P_{n}$ : load for $M_{n}$.

4.3. Validation of Flexural Strength Model. Verifying suitability of flexural strength models, test results were compared with assumed flexural strength model. Comparison results were listed in Table 4 . As expected, model type 1 which has triangular stress block has shown comparatively high accuracy. However, this model overestimated moment capacity of section. Overestimation of this model was caused by large area of tensile stress block and higher value of moment arm. Higher value of moment arm can be derived by the existence of residual strength. Model type 2 also has shown acceptable accuracy but this model underestimated moment capacity. Underestimation of this model was caused by the relatively low level of tensile stress block area and lower value of moment arm for tensile stress block. This smaller moment arm was derived by the end of the stress block. Model type 3 which has rectangular tensile stress block has shown low accuracy and overestimation.

Generally, rectangular stress block has shown deeper neutral axis depth from compression fiber than triangular stress block; moment arm has lower value than the cases of triangular stress block types. Model types with ACI rectangular stress block have low accuracy on neutral axis depth, tensile strain of reinforcements, and moment capacity. This phenomenon was caused by the larger area of stress block than triangular stress block. However, Models with ultra high performance concrete stress block parameters, which are derived from test results [12], have shown relatively high accuracy with all types of tensile stress block. This model, especially, predicts neutral axis depth more accurately than other models. As discussed above, the most accurate tensile stress block was also stress block including residual strength of concrete.

Considering low ductility, which is caused by explosive failure of ultra high strength concrete, the most appropriate model for design of flexural strength is type 8 which was modelled by UHPC-rectangular stress block parameters under compression and tension softening considering model under tension. Type 7 also can be used for design purposes but in this case strength reduction factor is carefully considered with material properties.

\section{Validation of Flexural Strength Models with Previous Researches}

For the verification of wide range applicability of assumed model, existing test results [6-8] of ultra high performance concrete members were compared with assumed models. Because a few number of specimens exist, only 22 test results were compared with suggested model. Specifications for collected test results were shown in Table 5. Test results from each research were summarized in Table 5. All test specimens experienced yielding of reinforcement before reaching peak load. They failed with flexural failure at the center of the specimens. Collected test specimens have 0.27 to $2.36 \%$ of tensile reinforcement ratio and $80 \sim 200 \mathrm{MPa}$ of compressive strength of concrete. Fiber contents were distributed from $0.5 \%$ to $2.0 \%$.

According to the test results of Ashour et al. [6], effect of the fibers to flexural strength is independent of the amount of reinforcement but additional moment is proportional to concrete compressive strength. Therefore, compressive strength 


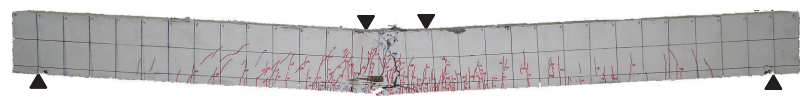

(a) Final stage of failure

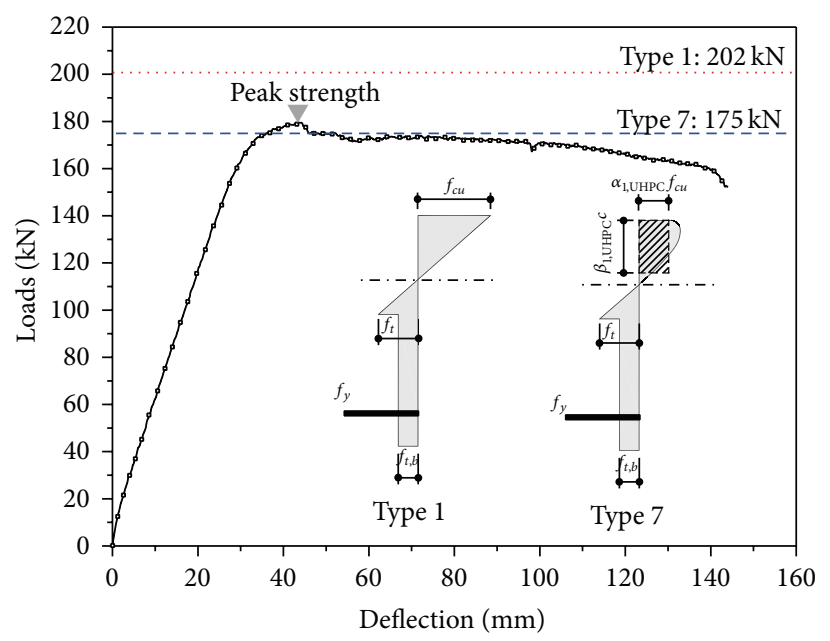

(b) Load-deflection relation

FIgURE 5: Test results.

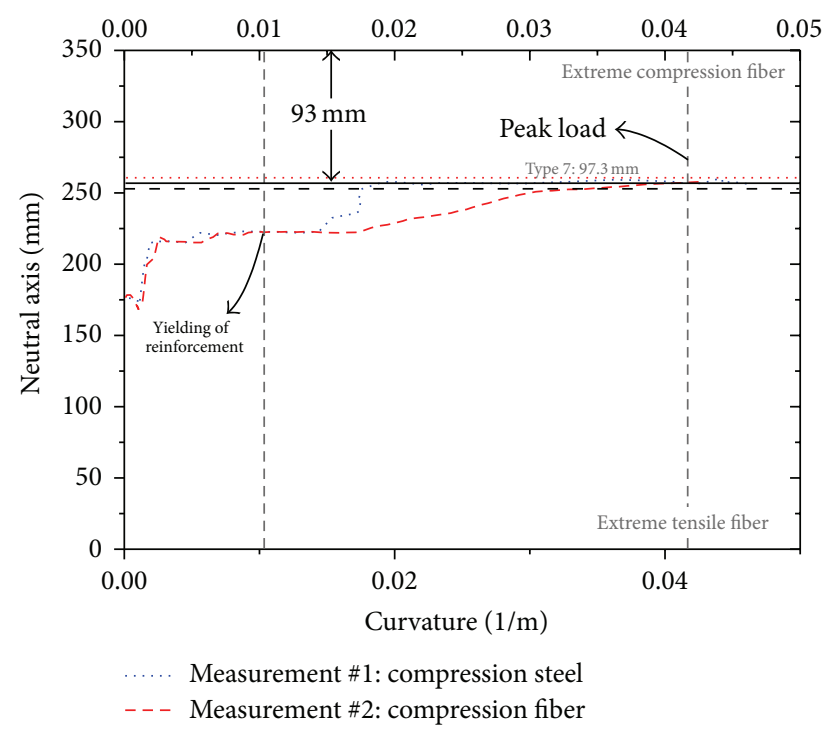

FIgURE 6: Change of neutral axis depth.

of concrete should be considered in flexural strength model. Dancygier and Savir [7] investigated flexural strength of fiber reinforced concrete with conventional reinforcement ratio lower than $1 \%$. Fiber length, which affects reinforcing index (RI $=V_{f} L_{f} / D_{f}$, where $V_{f}$ is fibre volume fraction, $L_{f}$ is fiber length, and $D_{f}$ is fiber diameter), directly changes the flexural strength of section. Generally, fiber length changes the failure mode of fiber reinforced concrete under bending, especially after peak load. Therefore, material behavior under tension should be considered for flexural strength calculation. Yang et al. [8] investigated about placing method and reinforcement ratio especially for ultra high performance concrete which have compressive strength around $200 \mathrm{MPa}$. According to this research, reinforcement ratio also affects the flexural strength and ductility although members have much higher compressive strength of concrete. Some of test results did not evaluate prediction methods previously investigated $[2,4,5]$.

Therefore, all assumed models were examined with test results. Comparison of test results with flexural strength models was shown in Figures 7(a)-7(d) and descriptive statistical data were shown in Table 6. Existing flexural strength model which was reviewed in this paper only has accuracy when using comparatively lower compressive strength of concrete $(80 \sim 100 \mathrm{MPa})$ as shown in Figure $7(\mathrm{a})$. The variance of this model increases with increase of compressive strength of concrete. As shown in Figures 7(b) and 7(c), types 1 to 6 still have overestimated the flexural strength of ultra high performance concrete. However, when tension softening model was applied, accuracy comparatively increased. Types 7 to 9 which use the newly developed rectangular stress block show more accuracy and safety rather than the other 9 models. Types 7 and 8 especially have high accuracy over the range of ultra high performance concrete. Because type 8 which uses tension softening model underestimates the flexural capacity, it would be used for safe design of ultra high performance concrete members.

\section{Conclusion}

The following conclusions can be made from the statistical investigation, analytical works, and tests for FRUHSC for flexural strength:

(1) Stress distribution of ultra high performance concrete under compression shaped as triangle. Under tensile stress, stress distribution of ultra high performance concrete can be varied with fiber contents or shape.

(2) Nine-flexural strength models were evaluated. For the conservative estimation, ultimate strain at compression fiber was assumed to be 0.003 . These flexural strength models were evaluated using assumed stress distribution. 
TABLE 5: Previous test results.

\begin{tabular}{|c|c|c|c|c|c|c|c|c|c|c|c|}
\hline Specimen & $\begin{array}{c}b \\
(\mathrm{~mm})\end{array}$ & $\begin{array}{c}h \\
(\mathrm{~mm})\end{array}$ & $\begin{array}{c}d \\
(\mathrm{~mm})\end{array}$ & $\begin{array}{c}A_{s t} \\
\left(\mathrm{~mm}^{2}\right)\end{array}$ & $\begin{array}{c}\rho \\
(\%)\end{array}$ & $\begin{array}{c}f_{c u} \\
(\mathrm{MPa})\end{array}$ & $\begin{array}{l}V_{f} \\
(\%)\end{array}$ & $\begin{array}{c}D_{f} \\
(\mathrm{~mm})\end{array}$ & $\begin{array}{c}L_{f} \\
(\mathrm{~mm})\end{array}$ & $\begin{array}{c}f_{y} \\
(\mathrm{MPa})\end{array}$ & $\begin{array}{c}P_{u} \\
(\mathrm{kN})\end{array}$ \\
\hline \multicolumn{12}{|c|}{ Ashour et al. [6] } \\
\hline B-0.5-M2 & 200 & 250 & 215 & 509 & 1.18 & 82 & 0.5 & 0.8 & 60 & 530 & 49.1 \\
\hline B-1.0-M2 & 200 & 250 & 215 & 509 & 1.18 & 87 & 1 & 0.8 & 60 & 530 & 54.2 \\
\hline B-0.5-M3 & 200 & 250 & 215 & 763 & 1.78 & 82 & 0.5 & 0.8 & 60 & 530 & 69.5 \\
\hline B-1.0-M3 & 200 & 250 & 215 & 763 & 1.78 & 87 & 1 & 0.8 & 60 & 530 & 71.4 \\
\hline B-0.5-M4 & 200 & 250 & 215 & 1018 & 2.37 & 82 & 0.5 & 0.8 & 60 & 530 & 88.1 \\
\hline B-1.0-M4 & 200 & 250 & 215 & 1018 & 2.37 & 87 & 1 & 0.8 & 60 & 530 & 89.7 \\
\hline B- $0.5-\mathrm{H} 2$ & 200 & 250 & 215 & 509 & 1.18 & 107 & 0.5 & 0.8 & 60 & 530 & 48.5 \\
\hline B-1.0-H2 & 200 & 250 & 215 & 509 & 1.18 & 111 & 1 & 0.8 & 60 & 530 & 53.7 \\
\hline B- $0.5-\mathrm{H} 3$ & 200 & 250 & 215 & 763 & 1.78 & 107 & 0.5 & 0.8 & 60 & 530 & 69.6 \\
\hline B-1.0-H3 & 200 & 250 & 215 & 763 & 1.78 & 111 & 1 & 0.8 & 60 & 530 & 74.1 \\
\hline B- $0.5-\mathrm{H} 4$ & 200 & 250 & 215 & 1018 & 2.37 & 107 & 0.5 & 0.8 & 60 & 530 & 89.1 \\
\hline B-1.0-H4 & 200 & 250 & 215 & 1018 & 2.37 & 111 & 1 & 0.8 & 60 & 530 & 93.5 \\
\hline \multicolumn{12}{|c|}{ Dancygier and Savir [7] } \\
\hline H5-F2-1_35 & 200 & 300 & 273 & 151 & 0.28 & 129 & 0.75 & 0.9 & 35 & 480 & 23.6 \\
\hline H5-F2-1_60 & 200 & 300 & 273 & 151 & 0.28 & 124 & 0.75 & 0.9 & 60 & 480 & 27.3 \\
\hline H8-F2-1_35 & 200 & 300 & 273 & 302 & 0.55 & 124 & 0.75 & 0.9 & 35 & 480 & 38.9 \\
\hline H8-F2-1_60 & 200 & 300 & 273 & 302 & 0.55 & 122 & 0.75 & 0.9 & 60 & 480 & 37.2 \\
\hline H5-F2-1_35_3 & 200 & 300 & 273 & 151 & 0.28 & 122 & 0.75 & 0.9 & 35 & 616 & 28.1 \\
\hline \multicolumn{12}{|c|}{ Yang et al. [8] } \\
\hline R12-1 & 180 & 270 & 235 & 253 & 0.60 & 191 & 2 & 0.2 & 13 & 400 & 77.0 \\
\hline R13-1 & 180 & 270 & 235 & 380 & 0.90 & 192 & 2 & 0.2 & 13 & 400 & 86.3 \\
\hline R14-1 & 180 & 270 & 235 & 507 & 1.20 & 197 & 2 & 0.2 & 13 & 400 & 103.1 \\
\hline R23-2 & 180 & 270 & 220 & 760 & 1.20 & 196 & 2 & 0.2 & 13 & 400 & 116.5 \\
\hline
\end{tabular}

$b$ : beam width, $h$ : beam height, $d$ : effective depth of beam, $A_{s t}$ : tensile reinforcement area, $\rho$ : reinforcement ratio, $f_{c u}:$ compressive strength of concrete, $V_{f}$ : volume fraction of steel fiber, $D_{f}$ : fiber diameter, $L_{f}$ : fiber length, $f_{y}$ : yield strength of reinforcement, and $P_{u}$ : test results (load at ultimate failure).

TABLE 6: Descriptive statistics on collected test data (test/prediction).

\begin{tabular}{lcccccc}
\hline ID & Mean & Median & SD & Var. & COV & IAE \\
\hline ACI544 & 1.24 & 1.06 & 0.34 & 0.115 & 0.27 & 17.20 \\
Imam & 1.22 & 1.01 & 0.45 & 0.201 & 0.37 & 19.83 \\
Lim & 1.13 & 1.04 & 0.26 & 0.068 & 0.23 & 14.15 \\
Type 1 & 0.81 & 0.90 & 0.20 & 0.040 & 0.24 & 33.56 \\
Type 2 & 1.18 & 1.07 & 0.29 & 0.086 & 0.25 & 16.72 \\
Type 3 & 0.70 & 0.76 & 0.16 & 0.024 & 0.22 & 46.54 \\
Type 4 & 0.87 & 0.91 & 0.14 & 0.021 & 0.16 & 15.63 \\
Type 5 & 1.18 & 1.06 & 0.30 & 0.091 & 0.25 & 16.62 \\
Type 6 & 0.69 & 0.75 & 0.15 & 0.023 & 0.22 & 49.18 \\
Type 7 & 0.90 & 0.95 & 0.15 & 0.021 & 0.16 & 10.30 \\
Type 8 & 1.11 & 1.07 & 0.24 & 0.060 & 0.22 & 11.42 \\
Type 9 & 0.73 & 0.77 & 0.14 & 0.021 & 0.20 & 35.58 \\
\hline
\end{tabular}

SD: standard variation, Var.: variance, COV: coefficient of variation, and IAE: integrated absolute error.

(3) The most accurate model of ultra high performance concrete under compression is triangular. Because ultra high performance concrete has large elastic area, failure occurred with the same time experiencing ultimate strength. However, for the safe design of section, flexural strength model which uses modified rectangular stress blocks, considering mechanical characteristics of UHPC, should be used.

(4) Evaluating validation process using test result of this study and previous researches, existing flexural strength calculation models cannot accurately and safely predict the flexural strength of ultra high strength concrete specimens especially for compressive strength larger than $100 \mathrm{MPa}$. However, flexural strength model suggested in this study can provide conservative and highly accurate ( $10 \%$ of error) results.

\section{Conflict of Interests}

The authors declare that there is no conflict of interests regarding the publication of this paper.

\section{Acknowledgments}

This research was supported by a grant (15CTAP-C09735601) from Creative Challenge Research Program funded by Ministry of Land, Infrastructure and Transport of 

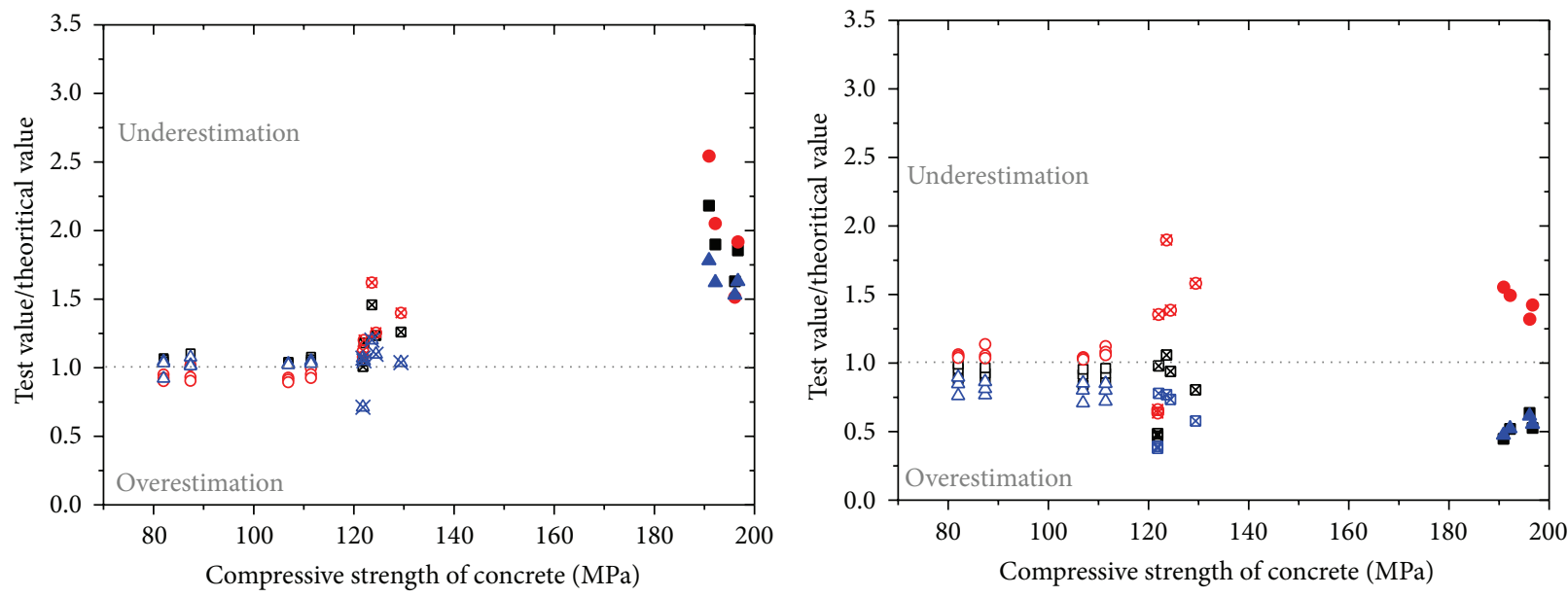

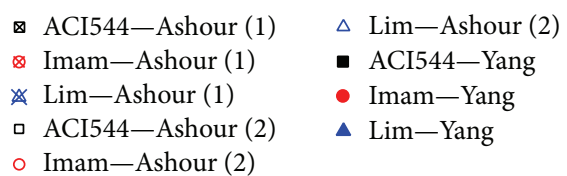

(a) Existing model

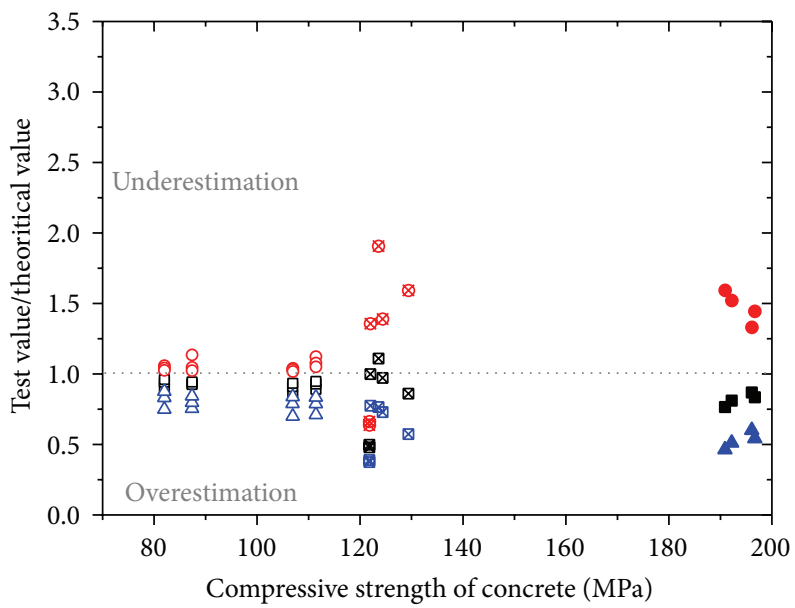

๑ Type 4-Ashour

* Type 5-Ashour

$\otimes$ Type 6-Ashour

- Type 4-Dancygier

- Type 5-Dancygier $\triangle$ Type 6-Dancygier

- Type 4-Yang

- Type 5-Yang

- Type 6-Yang

(c) Assumed types 4 6

๑ Type 1-Ashour

* Type 2-Ashour

$\otimes$ Type 3-Ashour

- Type 1-Dancygier

- Type 2-Dancygier

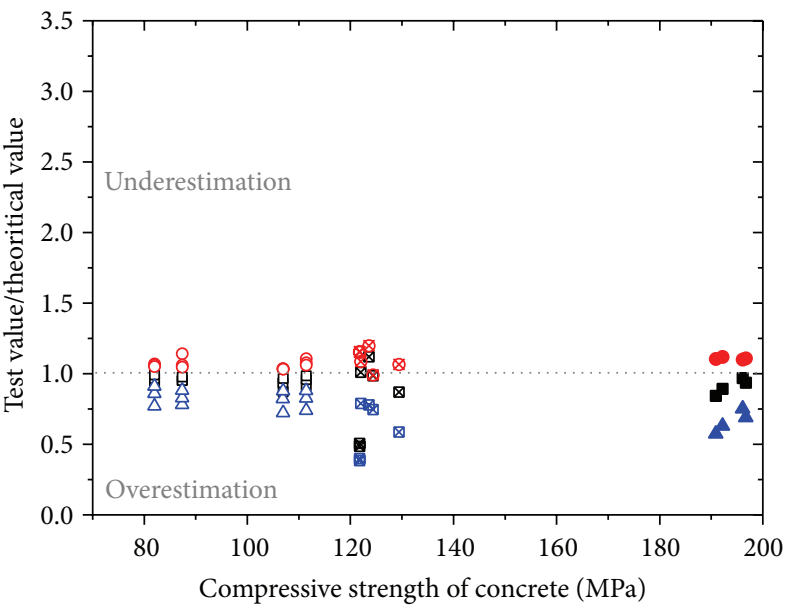

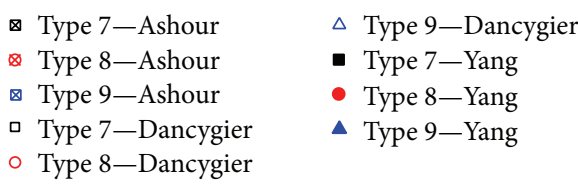

(d) Assumed types 7 9

FIGURE 7: Applicability verification for prediction model.

Korean government and National Research Foundation of Korea(NRF) funded by the Ministry of Science, ICT and Future Planning (no. NRF-2014R1A2A1A11051049).

\section{References}

[1] ACI Committee, "Building code requirements for structural concrete and commentary," ACI 318-11, American Concrete Institute, Farmington Hills, Mich, USA, 2011.

[2] American Concrete Institute Committee 544, "Design considerations for steel fiber reinforced concrete," International Concrete Abstracts Portal, vol. 85, no. 5, pp. 563-579, 1988.
[3] C. H. Henager and T. J. Doherty, "Analysis of reinforced fibrous concrete beams," Journal of the Structural Division, vol. 102, no. 1, pp. 177-188, 1976, ASCE Proceedings.

[4] M. Imam, L. Vandewalle, and F. Mortelmans, "Shear-moment analysis of reinforced high strength concrete beams containing steel fibres," Canadian Journal of Civil Engineering, vol. 22, no. 3, pp. 462-470, 1995.

[5] T. Y. Lim, P. Paramasivan, and S. L. Lee, "Shear and moment capacity of reinforced steel fiber concrete beams," Magazine of Concrete Research, vol. 39, no. 140, pp. 148-160, 1987.

[6] S. A. Ashour, F. F. Wafa, and M. I. Kamal, "Effect of the concrete compressive strength and tensile reinforcement ratio 
on the flexural behavior of fibrous concrete beams," Engineering Structures, vol. 22, no. 9, pp. 1145-1158, 2000.

[7] A. N. Dancygier and Z. Savir, "Flexural behavior of HSFRC with low reinforcement ratios," Engineering Structures, vol. 28, no. 11, pp. 1503-1512, 2006.

[8] I. H. Yang, C. Joh, and B.-S. Kim, "Structural behavior of ultra high performance concrete beams subjected to bending," Engineering Structures, vol. 32, no. 11, pp. 3478-3487, 2010.

[9] RILEM and Final recommendations of TC 162-TDF, “Test and design methods for steel fibre reinforced concrete, $\sigma-\varepsilon$ design method," Materials and Structures, vol. 36, pp. 560-565, 2003.

[10] European Committee for Standardization, Eurocode 2 (EC2): Design of Concrete Structures, 2004.

[11] AFGC Groupe de Travail BFUP. SETRA-AFGC, Ultra High Performance Fiber-Reinforced Concretes: Interim Recommendation, 2002.

[12] B. I. Bae, C. S. Choi, and H. K. Choi, "Evaluation of rectangular stress block parameters of reactive powder concrete members," Journal of the Architectural Institute of Korea, vol. 28, no. 7, pp. 3-11, 2012.

[13] R. N. Swamy and S. A. Al-Ta'an, "Deformation and ultimate strength in flexure of reinforced concrete beams made with steel fibre concrete," Journal of the American Concrete Institute, vol. 78, no. 5, pp. 395-405, 1981. 

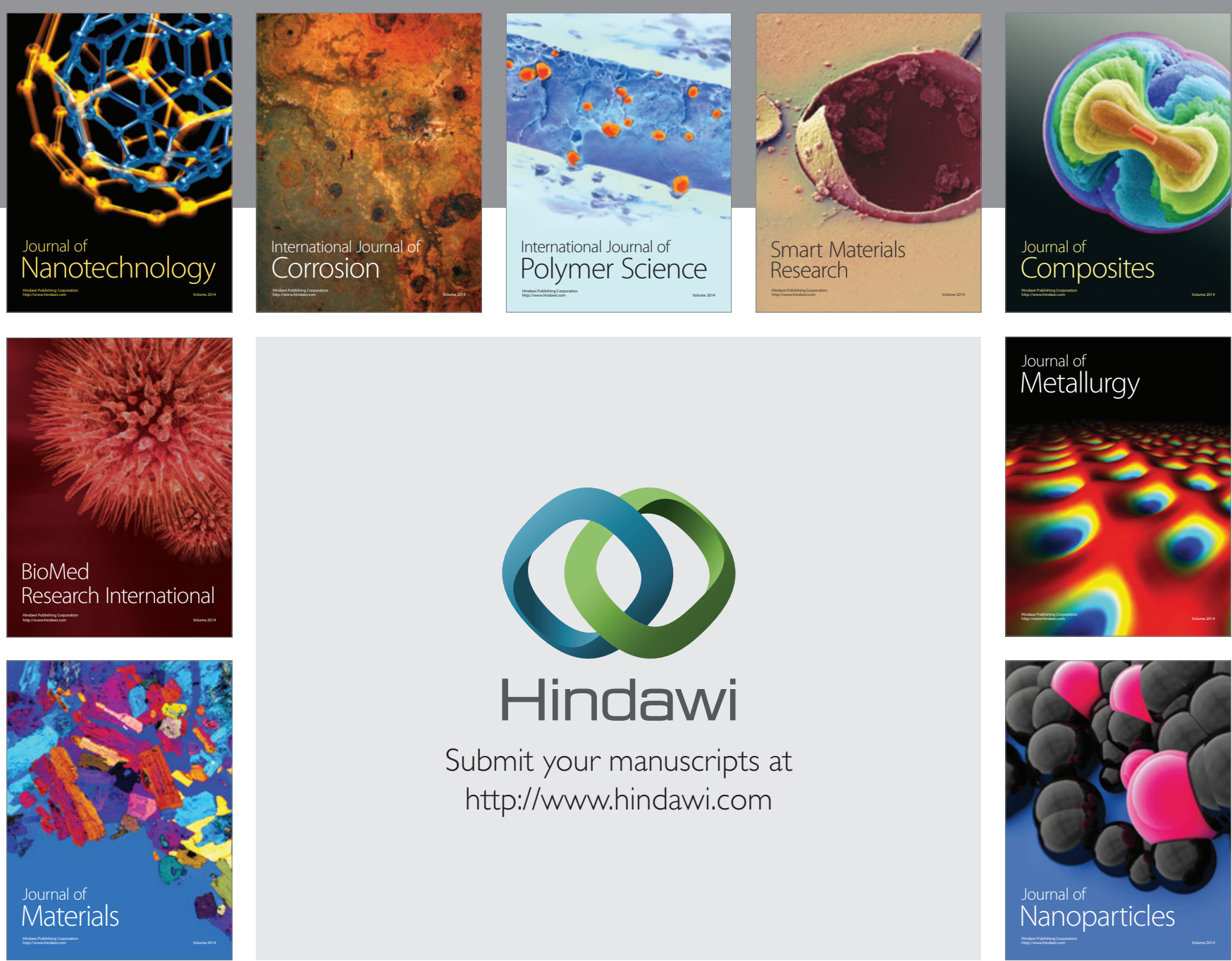

\section{Hindawi}

Submit your manuscripts at

http://www.hindawi.com

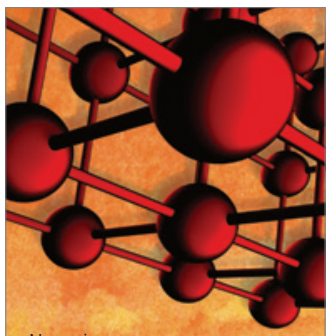

Materials Science and Engineering
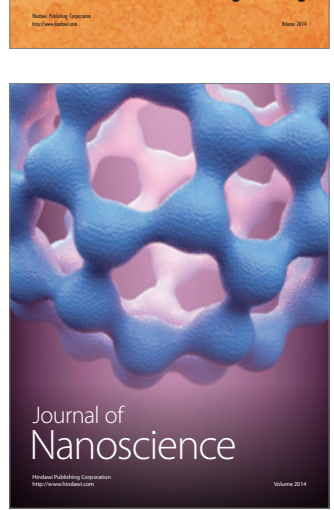
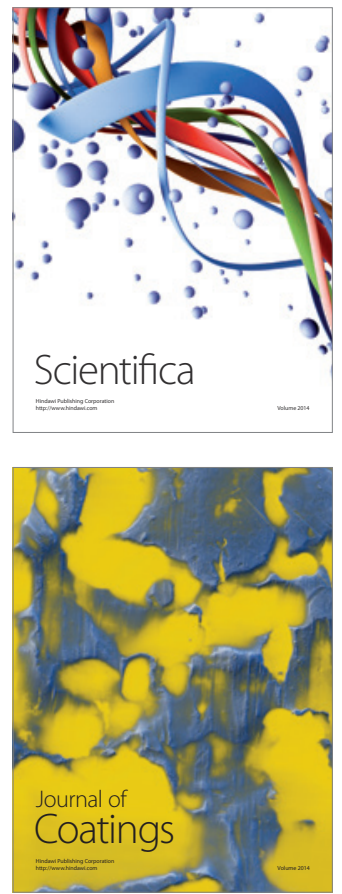
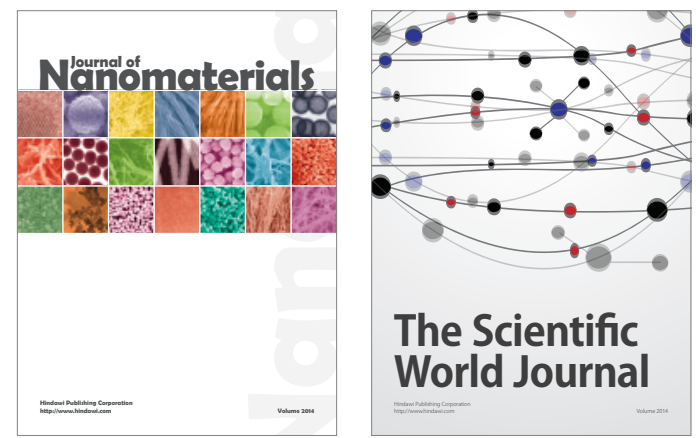

The Scientific World Journal
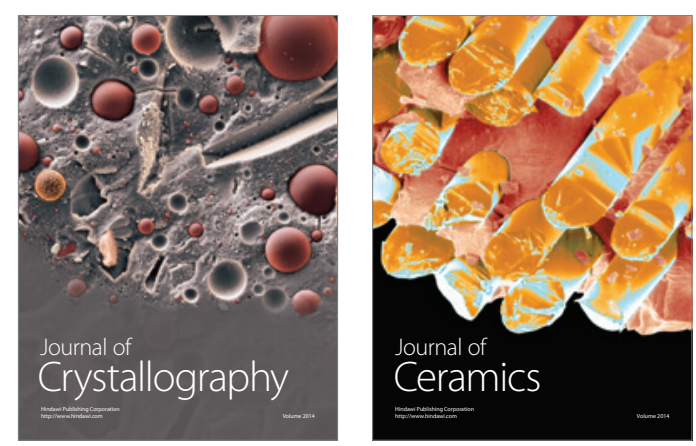
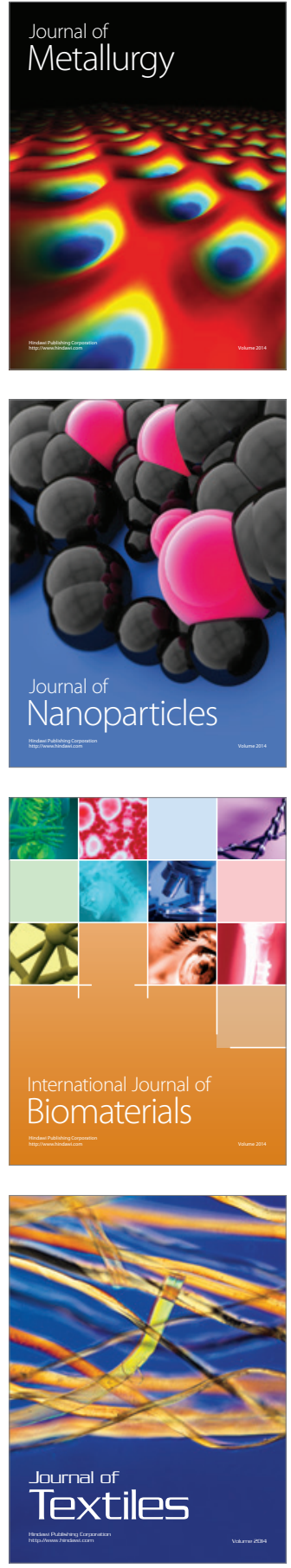